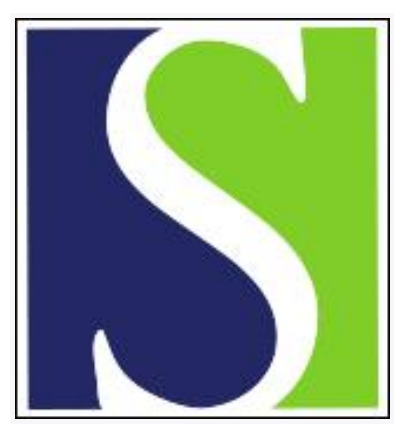

Scand J Work Environ Health 1995;21(4):289-292

https://doi.org/10.5271/sjweh.40

Issue date: Aug 1995

\title{
Scleroderma and occupational exposure
}

by Bovenzi M, Barbone F, Betta A, Tommasini M, Versini W

Key terms: case-referent study; chemical; epidemiology; hand-arm vibration; localized sclerosis; silica; solvent; systemic sclerosis

This article in PubMed: www.ncbi.nlm.nih.gov/pubmed/8553004

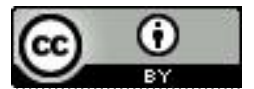




\title{
Scleroderma and occupational exposure
}

\author{
by Massimo Bovenzi, MD, ${ }^{1}$ Fabio Barbone, MD, ${ }^{2}$ Alberto Betta, MD, ${ }^{3}$ Michele Tommasini, MD, ${ }^{3}$ \\ Walter Versini, $M D^{3}$
}

Bovenzi M, Barbone F, Betta A, Tommasini M, Versini W. Scleroderma and occupational exposure. Scand J Work Environ Health 1995;21:289-92.

\begin{abstract}
Objectives A case-referent study was conducted in the province of Trento, Italy, to investigate the possible association between occupational exposure and scleroderma (systemic and localized variants).

Methods Twenty-one cases of scleroderma were ascertained from the computerized admission files of all of the local hospitals from 1976 to 1991. For each case, two age- and gender-matched referents were selected that were discharged from the hospital on the same day as the case. The subjects were interviewed with a structured questionnaire which included items for personal, work, and medical history. Exposure to organic solvents, other selected chemicals, silica dust, and hand-arm vibration was carefully investigated.

Results A significant association was found between exposure to organic solvents (aromatic hydrocarbons) and scleroderma [odds ratio (OR) 9.28, 95\% confidence interval $(95 \% \mathrm{CI}) 1.08-243.8$ ]. For the men, the OR for exposure to silica was $5.20(95 \% \mathrm{CI} 0.48-74.1)$, whereas for the women it was 2.11 (95\% CI $0.20-22.0)$ for exposure to other selected chemicals.

Conclusions The results of this case-referent study are consistent with those of previous case reports on the important role of occupation in the etiology of scleroderma. In particular, our findings confirm that exposure to organic solvents and silica is associated with this rare connective tissue disease.
\end{abstract}

Key terms case-referent study, chemicals, epidemiology, hand-arm vibration, localized sclerosis, silica, solvents, systemic sclerosis.

Scleroderma is a rare disorder of the connective tissue of various organs. It is characterized by microvascular alterations and massive deposition of collagen which cause induration and thickening of the skin, musculoskeletal manifestations, and visceral involvement, especially of the gastrointestinal tract, lungs, heart, and kidneys (1, $2)$. The etiology of scleroderma is still relatively unknown, although an association with occupational exposure to various chemicals and physical agents has been suggested in a number of case reports. Rather consistently, silica exposure has been reported in several cases of scleroderma in various countries, particularly among miners who, in many instances, have also been exposed to hand-arm vibration (3-6). Exposure to silica has also been found to be associated with scleroderma in the only nested case-referent study which has been published on the subject (7). Exposure to chemical compounds such as organic solvents (8-12), formaldehyde (13), epoxy resins (14), and vinyl chloride (15) has also been found among scleroderma cases. However, none of the reports originated from investigations conducted within the frame of a well-designed epidemiologic case-referent or cohort study. To determine whether certain occupations or occupational exposures are risk factors for scleroderma, we conducted a case-referent study based on 16 years of observation of the general population of the administrative province of Trento, Italy (460 000 inhabitants).

\section{Subjects and methods}

Among the patients who had been admitted to all of the hospitals of the province from 1976 to 1991, we selected those who were discharged with a diagnosis of musculoskeletal disorders or connective tissue diseases (International Classification of Diseases, ninth revision, codes 701.0, 710-739.9). From a computerized database system, 527 cases were identified. The clinical 
records of each patient were obtained and inspected to verify the correspondence with the diagnostic code. $\mathrm{Pa}$ tients affected with systemic sclerosis were identified according to the diagnostic criteria of the American Rheumatism Association (1). The patients had to have symptoms corresponding to the single major diagnostic criterion (ie, proximal scleroderma) or two or more minor criteria (ie, sclerodactyly, digital pitting scars on the fingertips or loss of substance of the distal finger pad, and bibasilar pulmonary fibrosis). Patients with localized variants of scleroderma (morphea, linear scleroderma, and generalized morphea) were also included in the study. Those who did not reside in the province or were younger than 18 years at diagnosis were excluded from the study. The final group comprised 21 subjects, 16 women ( 9 with systemic sclerosis, 7 with localized variants) and 5 men ( 1 with systemic sclerosis, 4 with localized variants).

With the same database system, for each case, two age- and gender-matched referents were selected from the patients who had been discharged from the hospital on the same day of the case and who were not affected with musculoskeletal or connective tissue diseases.

All of the subjects were interviewed in person by a trained investigator who was not aware of the case-referent status. A structured questionnaire containing the following items was used: personal characteristics, smoking and drinking habits, use of medicines (2), presence of pets in the household (16), complete medical and occupational history. Women were also questioned about silicone implants and cosmetic surgery (paraffin, processedpetrolatum jelly) (17). Occupational exposure to organic solvents (aliphatic and aromatic hydrocarbons), other chemicals (formaldehyde, epoxy resins, and vinyl chloride), silica dust, welding fumes (18), and hand-arm vibration from powered processes or tools was carefully investigated. The subjects were allocated into the various exposure categories by two occupational physicians who were blinded about the case-referent condition. A minimum criterion of six months was required for exposure duration.
To evaluate the association between scleroderma and risk factors, the conditional maximum likelihood estimate of the odds ratio (OR) was calculated with the use of StatXact software (19). Owing to the sparseness of the data, $95 \%$ confidence intervals $(95 \% \mathrm{CI})$ were assessed by the mid-p method $(20,21)$.

\section{Results}

The distribution of cases and referents according to occupational exposures is displayed in table 1 . Since most of the subjects, especially among the men, had had multiple exposures to occupational risk factors, the categories of exposure were not mutually exclusive. Among the men, an increased odds ratio (OR) for scleroderma was observed for organic solvents, silica dust, and hand-transmitted vibration. Exposure to solvents and other chemicals was associated, albeit not significantly, with scleroderma among the women. None of the cases or the referents reported exposure to welding fumes. When the men and women were combined, a statistically significant excess risk was found for exposure to solvents (OR 9.28, $95 \%$ CI 1.08-243.8). Of the four cases exposed to solvents, two were systemic scleroses and two were localized variants. A slightly increased odds ratio was also seen for other chemicals, silica, and hand-arm vibration, but the excess risk was not significant. Alcohol consumption, cigarette smoking, and contact with pets did not show an association with scleroderma, nor were there confounders or effect modifiers of the association with occupational exposures. A history of silicone implants and cosmetic surgery was not reported by any of the women included in the study. The study subjects did not use any of the drugs implicated in the development of scleroderma (eg, appetite suppressants, bleomycin, carbidopa, pentazocine)

\section{Discussion}

According to the data of this study, the annual incidence of scleroderma in the adult population of the province of

Table 1. Exposure among the cases of scleroderma and the matched referents with the men and women both separately and combined. Conditional maximum likelihood estimate of the odds ratios (OR) and mid-p $95 \%$ confidence intervals $(95 \% \mathrm{Cl})$ are reported.

\begin{tabular}{|c|c|c|c|c|c|c|c|c|c|c|c|c|}
\hline \multirow[t]{2}{*}{ Exposure } & \multicolumn{4}{|c|}{ Men } & \multicolumn{4}{|c|}{ Women } & \multicolumn{4}{|c|}{ Total } \\
\hline & $\begin{array}{l}\text { Cases } \\
(N=5)\end{array}$ & $\begin{array}{c}\text { Refer- } \\
\text { ents } \\
(\mathrm{N}=10)\end{array}$ & OR & $95 \%$ C & $\begin{array}{l}\text { Cases } \\
(\mathrm{N}=16)\end{array}$ & $\begin{array}{l}\text { Refer- } \\
\text { ents } \\
(N=32)\end{array}$ & $\mathrm{OR}$ & $95 \% \mathrm{Cl}$ & $\begin{array}{l}\text { Cases } \\
(N=21)\end{array}$ & $\begin{array}{l}\text { Refer- } \\
\text { ents } \\
(N=42)\end{array}$ & OR & $95 \% \mathrm{Cl}$ \\
\hline Solvents & 3 & - & $\infty$ & $2.39-\infty$ & 1 & 1 & 2.03 & $0.05-83.0$ & 4 & 1 & 9.28 & $1.08-243.8$ \\
\hline Other chemicalsa & - & 1 & 0 & $0-18.0$ & 2 & 2 & 2.11 & $0.20-22.0$ & 2 & 3 & 1.36 & $0.15-9.88$ \\
\hline Silica & 3 & 2 & 5.20 & $0.48-74.1$ & - & 1 & 0 & $0-18.0$ & 3 & 3 & 2.14 & $0.34-13.6$ \\
\hline Hand-arm vibration & 2 & 3 & 1.51 & $0.12-74.1$ & - & - & 0 & & 2 & 3 & 1.36 & $0.15-9.88$ \\
\hline
\end{tabular}

a Formaldehyde, epoxy resins, vinyl chloride. 
Trento was estimated to be 1.5 cases per million among the men and 5.8 per million among the women. This finding is consistent with those reported in other investigations $(22,23)$. As expected, the disease was more frequent among the women than the men for both systemic sclerosis (9:1) and localized variants (1.75:1).

Because of the rarity of this disease, the epidemiology of scleroderma is very limited. Namely, the relation of scleroderma to occupational exposure is restricted to case reports $(3,5,6,9,11,12)$. The only case-referent study was published by Sluis-Cremer et al (7) in 1985 , who reported an association between progressive systemic sclerosis and the intensity of exposure to silica among white South African gold miners. Their study was based on 79 definite or probable cases of systemic sclerosis according to the criteria of the American Rheumatism Association, and it focused only on silica exposure and previous silicosis diagnosis.

To our knowledge, the present study is the first to be based on the general population. It addresses the several occupational exposures which have been linked to scleroderma in the descriptive literature. Furthermore, we have also investigated the possible role of nonoccupational risk factors. Our study tends to confirm a possible association between scleroderma and occupational exposure to silica dust among men. Taking into account the very low incidence of scleroderma among men, it is worth noting that both this study and the one by SluisCremer et al (7), as well as several other case reports (3-6), are consistent with the hypothesis that silica exposure may represent an important risk factor in the etiopathogenesis of scleroderma. The fact that we were able to find an excess risk for silica exposure in this study is due to the relatively high prevalence of occupational categories engaged in rock drilling and in the stone industry in the study area.

The main finding of this study was the significant association between scleroderma and exposure to organic solvents. The cases exposed to solvents included three male subjects (one with systemic sclerosis and two with localized variants) who had worked in the painting departments of metal or wood industries. They were in direct contact with both aromatic hydrocarbons such as ethylbenzene, toluene, xylene, and mixtures of paraffins, naphthenes, and alkyl aromatic hydrocarbons such as white spirits. The remaining case was a woman with systemic sclerosis who had been engaged in the printing industry with prevalent exposure to toluene. Among these subjects, the exposure duration to solvents ranged between 9 and 38 years. Walder (10) reported 11 patients with scleroderma who had been engaged in occupations with exposure to aromatic solvents (cleaning, painting, printing). His suggestion that the association between solvents and scleroderma is more than fortuitous seems to be supported by the results of this case-referent study.
It has been reported that scleroderma associated with exposure to aromatic hydrocarbons tends to be limited to the skin of the hands and feet $(10,24)$. This observation was only partially confirmed by our present study as two of the four solvent-exposed patients were affected with systemic sclerosis. It should be stressed that aromatic hydrocarbons are not only absorbed through the skin but also during inhalation owing to their high volatility. This phenomenon might cause both localized and multisystem involvement of the connective tissue. However, it cannot be excluded that our patients had also been exposed to other solvents such as chlorinated hydrocarbons (eg, trichloroethylene, perchloroethylene) or certain aliphatic compounds believed to be probable causative agents of generalized morphea and systemic sclerosis $(9$, 24). The use of white spirits might have played a role in the development of systemic scleroderma in at least one of our solvent-exposed patients.

Selection bias was not likely in this study. In fact, we have no reason to believe that the subjects with scleroderma who were occupationally exposed tended to be treated preferentially in the local hospitals as compared with hospitals outside of the province. In addition, their pattern of referral should not be different from that of the subjects with other conditions. It is also unlikely that white-collar workers or unemployed persons were overrepresented among the hospital referents as compared with the general population. The latter condition would overestimate the overall odds ratio for occupational exposure to chemical or physical agents, but it is unlikely because the referents were selected from patients with all diagnoses, including some which might have an occupational origin (eg, chronic respiratory disease, cancer, etc). Information bias should also not have been a problem in this study because interviewers and personnel involved in data coding were blinded about the case-referent status of the subject. In addition, the recall of occupational exposure should not have been differentially misclassified for the cases compared with the referents because both were affected with a disease which was severe enough to cause hospitalization. The only serious alternative explanation to a causal association between certain occupational exposures and scleroderma in this study is chance. Since the study was small due to the rarity of the disease, its results should be interpreted cautiously.

\section{References}

1. Subcommittee for Scleroderma Criteria of the American Rheumatism Association Diagnostic and Therapeutic Criteria Committee. Preliminary criteria for the classification of systemic sclerosis (scleroderma). Axthritis Rheum 1980;23:581-90.

2. Perez MI, Kohn SR. Systemic sclerosis. J Am Acad Dermatol 1993;28:525-47.

3. Erasmus LD. Scleroderma in gold miners on the Witwatersrand with particular reference to pulmonary manifesta- 
tions. S Afr Lab Clin Med 1957;3:209-31.

4. Rodnan GP, Benedek TG, Medsger TA, Cammarata RJ. The association of progressive systemic sclerosis (scleroderma) with coal miners' pneumoconiosis and other forms of silicosis. Ann Intern Med 1967;66:323-34.

5. Haustein UF, Ziegler V, Herrmann K, Mehlhorn J, Schmidt C. Silica-induced scleroderma. J Am Acad Dermatol 1990;22: 444-8.

6. Pelmear PL, Roos JO, Maehle WM. Occupationally-induced scleroderma. J Occup Med 1992;34:20-5.

7. Sluis-Cremer GK, Hessei PA, Nizdo EH, Churchill AR, Zeiss EA. Silica, silicosis, and progressive systemic sclerosis. Br J Ind Med 1985:4:838-43.

8. Sparrow GP. A connective tissue disorder similar to vinyl chloride disease in a patient exposed to perchlorethylene. Clin Exp Dermatol 1977;2:17-22.

9. Yamakage A, Ishikawa H. Generalized morphea-likescleroderma occurring in people exposed to organic solvents. Dermatologica 1982;165:186-93.

10. Walder BK. Do solvents cause scleroderma? Int J DermatoI $1983 ; 22: 157-8$

11. Lockey JE, Kelly CR, Cannon GW, Colby TV, Aldrich V, Livingston GK. Progressive systemic sclerosis associated with exposure to trichloroethylene. J Occup Med 1987;29:493 -6.

12. Brasington RD, Thorpe-Swenson AJ. Systemic sclerosis associated with cutaneous exposure to solvent: case report and review of the literature. Arthritis Rheum 1991;34:631 - 3.

13. Rush PJ, Chaiton A. Scleroderma, renal failure and death associated with exposure to urea formaldehyde foam insulation. J Rheumatol 1986;13:475.

14. Yamakage A, Ishikawa H, Saito Y, Hattori A. Occupational scleroderma-like disorders occurring in men engaged in the polymerization of epoxy resins. Dermatologica 1980;161:33 44.

15. Black C, Pereira S, McWhirter A, Welsh H, Laurent R. Genetic susceptibility to scleroderma-like syndrome in symptomatic and asymptomatic workers exposed to vinyl chloride. J Rheumatol 1986; 13: $1059-62$

16. Silman AJ, Jones S. Pet ownership: a possible risk factor for scleroderma. Br J Rheumatol 1990;29:494-5.

17. Kumagai Y, Shiokawa Y, Medsger T, Rodnan G. Clinical spectrum of connective tissue disease after cosmetic surgery: observations on 18 patients and a review of the Japanese literature. Arthritis Rheum 1984;27:1—12.

18. Fessel WJ. Scleroderma and welding. New Engl J Med 1977; 296-1537.

19. Cytel Software Corporation. StatXact: statistical software for exact nonparametric inference. Cambridge, MA: Cytel Software Corporation, 1992.

20. Mehta CR, Walsh SJ. Comparison of exact, mid-p, and Mantel-Haenszel confidence intervals for the common odds ratio actoss several $2 \times 2$ contingency tables. Am Stat 1992;46: $146-50$.

21. Emerson JD. Combining estimates of the odds ratio: the state of the art. Stat Methods Med Res 1994;3:157-78.

22. Medsger TA, Masi AT. Epidemiology of systemic sclerosis (scleroderma). Ann Intern Med 1971;74:714-21.

23. Medsger T. Epidemiology of progressive systemic sclerosis. Clin Rheum Dis 1979;5:15-25.

24. Owens GR, Medsger TA. Systemic sclerosis secondary to occupational exposure. Am J Med 1988:85:114—6.

Received for publication: 21 October 1994 